\title{
Ontario physicians get liability fee break
}

$\mathrm{T}$ he Canadian Medical Protection Association (CMPA) will tap its pool of "excess" assets to substantially reduce medical liability fees for Ontario doctors in 2012.

The reduction is the product of a negotiated agreement with the cashstrapped government of Ontario, which sought a reduction in its liability reimbursements for physicians and argued that the vast pool of CMPA assets over forecast liabilities for the Ontario region should be used to reduce physician fees in 2012 and thus, the amount that the government would have to shell out in liability subsidies. Under an Ontario Medical Association agreement with the government, the province picks up the cost of liability fees for its doctors in lieu of other forms of compensation for clinical services.

As a consequence of the negotiated agreement, medical liability fees for doctors in Ontario will plummet 52.7\% to $\$ 1111$ from $\$ 2422$, while charges for Quebec physicians will drop by $4.2 \%$ to $\$ 4150$ from $\$ 4332$. Doctors in all other parts of Canada will see their fees increase by $4.3 \%$ to $\$ 2784$ from $\$ 2670$. It will mark the third consecutive year that liability fees for Ontario doctors will decline, though the two previous reductions were nowhere near as substantial as those for 2012.

The differential fees are largely the product of CMPA's operation of essentially three different liability systems in the country, with funds for each funnelled into separate accounts. Fee levels are calculated according an actuarial estimate of current and future liabilities. In cases where claims against a province were lower than anticipated in a given year, doctors are allocated what are called "fee credits," which reduce the average fee they must pay in the following year.

The 2012 fee cut has stirred a "fair amount of angst" among members,

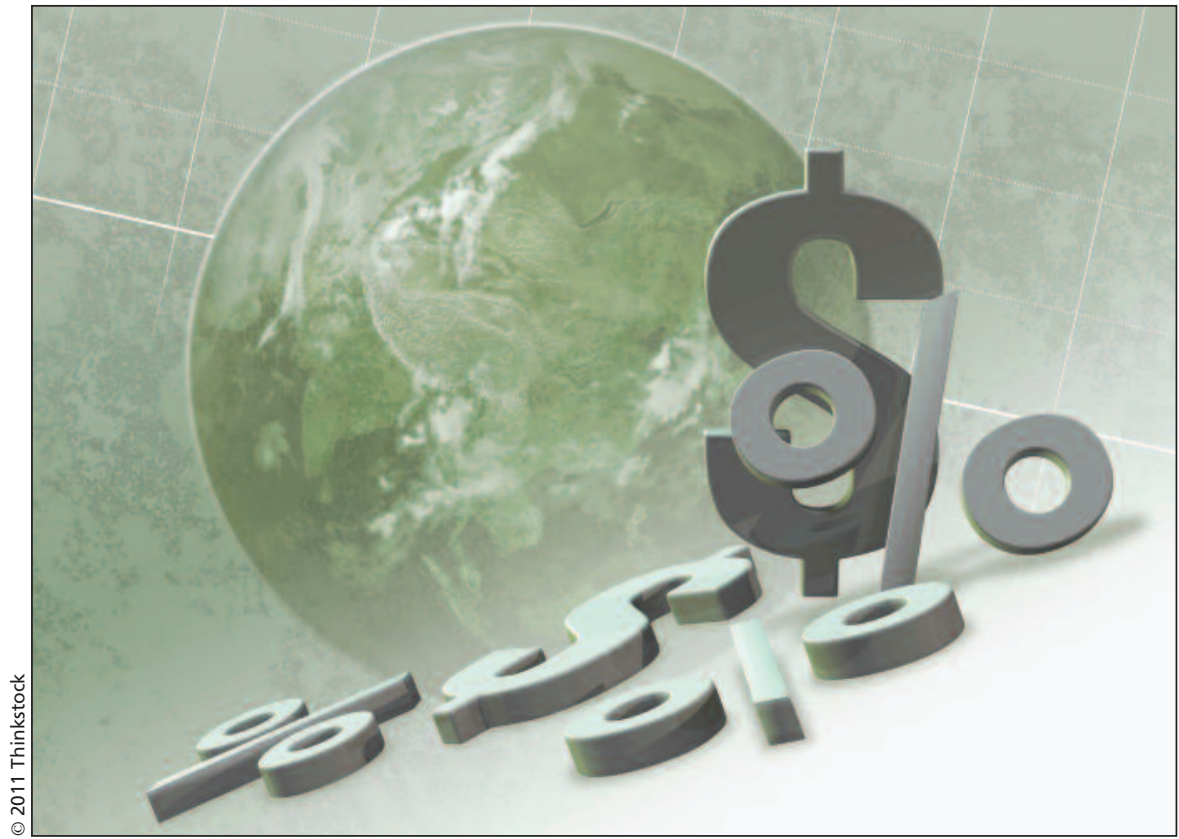

Medical liability fees for doctors in Ontario will plummet $\mathbf{5 2 . 7 \%}$ to $\$ 1111$ from $\$ 2422$, while charges for Quebec physicians will drop by $4.2 \%$ to $\$ 4150$ from $\$ 4332$ and those for doctors in all other parts of Canada will increase by $4.3 \%$ to $\$ 2784$ from $\$ 2670$.

CMPA Chief Executive Officer Dr. John Gray claimed, saying that some physicians see it as a "cash grab" by the province, while others worry that it will ultimately compromise the size of the region's reserve fund at a time when the economy could crash.

But they "don't see what's behind the numbers," Gray added. "We still have several hundred million dollars available for future fee credits, so it's not as though we've drained the accounts."

Gray also stressed that Ontario fees will eventually have to start rising. It's "not sustainable to keep charging such small fees."

Last year, CMPA saw a 3\% increase in the total number of newly opened legal actions against its members - the first after a decade of declining cases.

The association also reported a "marked increase" in the median damages paid per case in all regions, even after adjustments for inflation. Median damages in Ontario topped the charts at around $\$ 160000$ per case, compared to some $\$ 140000$ in the rest of Canada and under $\$ 100000$ in Quebec.

Delegates were also informed that CMPA's financial picture remains sound. The association took in $\$ 510$ million in 2010, while spending $\$ 347$ million, leaving a reserve of $\$ 163$ million. That allowed the association to increase its general reserves to $\$ 647$ million.

The CMPA's annual report also indicates that of 940 civil legal actions commenced in 2010, 96 went to trial but only 15 of those saw an outcome favouring a plaintiff. Some 278 actions were settled, while 526 were dismissed, discontinued or abandoned. CMPA membership rose to 80589 from 78 527. — Lauren Vogel, CMAJ

CMAJ 2011. DOI:10.1503/cmaj.109-3991 